\title{
DIGNIDADE, UMA QUESTÃO DE JUSTIÇA: A MULHER, A MATERNIDADE E O CÁRCERE
}

\author{
Taysa Matos do Amparo ${ }^{1}$ \\ Selma Pereira de Santana ${ }^{2}$
}

Resumo: O sistema prisional feminino é sustentado pelo desrespeito, estigmatização e discriminação de gênero, resultado de uma política criminal feita por e para homens. As mulheres grávidas ou amamentando são duplamente condenadas, tanto pelas mazelas dos presídios como pelo peso do julgamento social. Assim, tem-se por objetivo expor criticamente as dificuldades enfrentadas pelas mulheres grávidas nas penitenciárias do Brasil. Para tanto utilizou-se o método bibliográfico e de caráter exploratório, a partir do conjunto de obras e documentos escritos sobre o assunto, respondendo, assim, se os fatores inadequados para a gestação no cárcere, expõe mulheres e crianças a danos e experiências traumáticas.

PALAVRAS-CHAVE: Política Criminal; Criminologia; Dignidade da pessoa humana; Mulheres encarceradas; Maternidade no Cárcere.

\section{DIGNITY, A QUESTION OF JUSTICE: WOMAN, MOTHERHOOD AND PRISON}

\begin{abstract}
The female prison system is sustained by disrespect, stigmatization and gender discrimination resulting from a criminal policy made by and for men. Pregnant or breastfeeding women are doubly condemned, both for the penalties of prisons and the weight of social judgment. Thus, the objective is to critically expose the difficulties faced by pregnant women in penitentiaries in Brazil. For this, the bibliographic and exploratory method was used, based on the set of works and written documents on the subject, thus responding if the inadequate factors for gestation in the jail expose women and children to damages and traumatic experiences.
\end{abstract}

KEYWORDS: Criminal Policy; Criminology; Dignity of human person; Incarcerated women; Maternity in the Jail.

\footnotetext{
${ }^{1}$ Doutoranda em Direito pela Universidade Federal da Bahia - UFBA; Mestre em Gestão em Organizações Aprendentes pela Universidade Federal da Paraíba - UFPB; Especialista em Metodologia e Gestão do Ensino Superior; Graduada em Direito; Professora Substituta da Universidade Federal da Bahia - UFBA (2018); Coordenadora da Coluna Direito e Arte do Empório do Direito (http://emporiododireito.com.br/resultado); Membro do Instituto Baiano de Direito Processual Penal (IBADPP); Membro do Instituto Brasileiro de Ciências Criminais - IBCCRIM; Parecerista do IBCCRIM; Assessora da OAB da Bahia.

${ }^{2}$ Doutora em Ciências Jurídico-Criminais pela Faculdade de Direito da Universidade de Coimbra (2006). Mestre em Ciências Jurídico-Criminais por esta última Faculdade (2002). Especialista em Direito Penal e Direito Processual Penal pela Fundação Escola Superior do Ministério Público da Bahia, FESMIP. Especialista em Direito Administrativo pela Fundação Faculdade de Direito - FFD. Especialização em Processo pela Faculdade de Direito da Universidade Federal da Bahia - UFBA. Possui curso Aperfeiçoamento em Ciências Criminais e Dogmática Penal Alemã pela Georg-August Universität Göttingen, GAUG - Alemanha. Membro do IBCCRIM. Promotora do Ministério Público Militar da União em Salvador/Ba. Professora Associada de Direito Penal da Faculdade de Direito da Universidade Federal da Bahia (Graduação e Pós-Graduação). Coordenadora do Grupo de Pesquisas Justiça Restaurativa (cadastrado pelo CNPq).
} 


\section{INTRODUÇÃO}

Falar sobre a gravidez no cárcere e todos os traumas gerados - para mãe, filho (a) - é abordar questões delicadas do funcionamento do Sistema de Justiça Criminal e suas ineficácias. Os dados apresentados pelo Ministério da Justiça deixam claro que esse Sistema é ineficiente (desde a sua função intimidadora da pena até sua presunção de ressocialização) e encontra-se em plena falência estrutural. Segundo os dados investigados é possível afirmar que existe um complexo e inadequado Sistema de Justiça Criminal que não funciona nem na responsabilização das infrações, nem na produção de justiça, pois quando o direito penal se depara com pequenos delitos apresenta-se demasiadamente duro, e quando enfrenta crimes graves, muitas vezes, é praticamente inútil.

Nesse modelo arcaico de Justiça Criminal há uma desconsideração do "humano" - na aplicação e execução da pena - e quando se trata da mulher essa desconsideração é recheada por um arcabouço de preconceitos e conceitos morais do que é ser mulher ("normal") e viver em sociedade. Isso se acentua quando ela, além de ser criminosa, gera ou dá a luz na prisão. Por essa mácula, a maternidade, fase tão sublime, sua punição deverá vir não só dos diplomas legais, mas também de toda sociedade, aqui figurada na desestruturação de um sistema penal punitivista que através dos seus espaços físicos inadequados e procedimentos desumanos, firma aliança com os sistemas de controles sociais.

Analisando os dados do último relatório do Levantamento Nacional de Informações Penitenciárias - INFOPEN (2017) divulgado pelo Ministério da Justiça, é possível constatar que em 2016 a população prisional brasileira ultrapassou a marca de 700 mil pessoas privadas de liberdade, o que representa um aumento de $707 \%$ em relação ao total registrado no início da década de 90. Isso significa dizer que, entre os anos de 2000 e 2016, o Brasil teve um aumento de $157 \%$, já que em 2000 existiam 137 pessoas presas para cada grupo de 100 mil habitantes e em junho de 2016, eram 352,6 pessoas presas para cada 100 mil habitantes. (BRASIL/INFOPEN, 2017)

Ainda segundo o relatório, $40 \%$ das pessoas presas no Brasil não foram julgadas e condenadas. Outra informação importante apontada pelo relatório é quanto a faixa etária, cor e nível de escolaridade. A população prisional brasileira é formada por jovens entre 18 e 29 anos (55\%), há uma taxa de aprisionamento da ordem de 487,7 pessoas presas para cada grupo de 100 mil pessoas acima de 18. Também é possível afirmar que a grande maioria da 
população carcerária é formada por pessoas negras (64\%) e quanto ao grau de escolaridade, $17,75 \%$ da população prisional ainda não ingressou no ensino médio, tendo concluído, no máximo, o ensino fundamental (BRASIL/IFOPEN, 2017).

Outro dado fornecido pelo relatório citado, refere-se ao aprisionamento pelo tipo penal. Com base nesses dados, o tráfico de drogas é responsável por $28 \%$ das incidências penais pelas quais as pessoas privadas de liberdade foram condenadas ou aguardam julgamento, sendo que entre as mulheres, o crime de tráfico representa $62 \%$ dos registros, enquanto que para os homens é responsável somente por $26 \%$. Os crimes de roubo e furto somam $37 \%$ das incidências e os homicídios representam $11 \%$, sendo que nesses tipos penais o envolvimento dos homens chega a $38 \%$ e o das mulheres a $20 \%$.

No Brasil a participação de mulheres no crime, principalmente no tráfico de drogas, cresceu 698\% em 16 anos. Segundo dados mais recentes do Departamento Penitenciário Nacional (DEPEN, 2018), em período de 16 anos Em um período de 16 anos, entre 2000 e 2016, a taxa de mulheres presas aumentou em $455 \%$. Apesar desse aumento a grande maioria dos estabelecimentos prisionais foram projetados para homens $(74 \%)$, somente $7 \%$ atende ao público feminino e outros $16 \%$ são caracterizados como mistos. Isso evidencia que mesmo havendo um aumento significativo do envolvimento da mulher com o mundo do crime, os estabelecimentos penais continuam sendo pensados e feitos por homens e para homens, desconsiderando as peculiaridades do gênero. (BRASIL/IFOPEN MULHERES, 2018)

A análise dos dados da realidade prisional é essencial para a reflexão crítica da atuação de uma política criminal voltada para o controle e exclusão e não para a resolução dos conflitos. As graves violações de direitos fundamentais sofridas pela população carcerária, a superlotação dos espaços prisionais, a seletividade social e racial, a carência de assistência jurídica e de saúde, a ineficiente política de ressocialização e o alto índice de reincidência criminal compõem o quadro desolador das pessoas em situação de cárcere no país.

É importante destacar esse panorama do sistema penitenciário nacional para entender que o encarceramento feminino está diretamente relacionado a uma política criminal preconceituosa, a uma desestruturação social e ao aumento desenfreado da criminalidade. Além disso, as consequências e danos sociais sofridos com essas prisões deixam exposta a incapacidade do Estado em produzir e gerir políticas públicas que atendam mulheres em situação de vulnerabilidade e, consequentemente, aos seus filhos(as), pois, normalmente, as 
mulheres ingressam no mundo do crime, mais especificamente do tráfico, para sustentar a casa, ou ajudar o companheiro.

Com as prisões, muitas vezes arbitrárias e desnecessárias, os filhos(as) dessas mulheres passam a ter um "destino certo", o mundo do crime. Uma vez que sem a presença feminina, que antes "gerenciava" a casa, eles são "empurrados" para o abandono, o mundo das drogas ilícitas e a marginalidade. Assim, é possível afirmar que o dano social sofrido por essa prisão é irreversível e que tem, como principal vítima, toda a sociedade, já que a ineficácia da política criminal adotada (o ato representa mais que o fato) além de intimidadora, não possibilita minimizar seus efeitos nem produzir justiça.

É importante lembrar que a mulher vem de uma trajetória histórica de superação e quebra de paradigmas. Entretanto, enfrentar a cultura machista não é tarefa fácil, principalmente quando essa mulher vem da periferia, é negra e possui baixa escolaridade (perfil das mulheres presas no Brasil). Com isso, é natural que essas mulheres se envolvam com o mundo do crime para suprir uma lacuna deixada pelo companheiro ou para, junto com ele, atender as necessidades da casa, da família ou até mesmo de uma vida baseada na ostentação que o crime proporciona.

Dentro de um contexto social patriarcal ${ }^{3}$, ser mulher é estar submissa às regras sociais invioláveis. Ser mulher criminosa é romper com os padrões sociais masculinos, ser mãe e criminosa é violar com o que se tem de mais sagrado na sociedade, a maternidade. Sendo assim, seja pela falta de atendimento médico adequado, pelo tratamento desumano durante a gravidez, pelo ambiente insalubre ou pelo abrupto rompimento do vínculo afetivo e emocional com seu filho(a), a mulher que gera no carcere viverá as mazelas de um sistema penal segregador, descriminatório e seletivo, que reproduzirá as opressões oriundas da discriminação de classe, raça e, principalmente, de gênero, deixando claro que a política criminal adotada prioriza a punição, também moral, através de leis desiguais desde a sua criação até a execução.

$\mathrm{Na}$ Constituição brasileira, a dignidade humana está elencada como princípio estrutural do Estado, sendo assegurada como direito materialmente fundamental, além de inspirar uma série de outros direitos fundamentais. Entre esses direitos garantidos a todos (as), o da integridade física, moral e psíquica, independentemente de raça, sexo, orientação sexual,

3 Por patriarcalismo entende-se a organização da sociedade onde há o domínio dos homens sobre as mulheres (HARTMAN, 1988). 
idade, religião, origem social ou qualquer outra condição. Assim, a dignidade da pessoa humana é uma questão de justiça.

Diante desse contexto, o objetivo geral desse artigo é expor criticamente os danos e as experiências traumáticas vividas pelas mulheres encarceradas e seu bebê. Para tanto utilizouse o método de pesquisa bibliográfica e de caráter exploratório, a partir do conjunto de obras e documentos escritos sobre o assunto.

\section{A MULHER E A CRIMINALIDADE}

Para entender a relação da mulher com a criminalidade é preciso compreender que, historicamente, o direito penal não tinha a mulher como foco de atuação, uma vez que o controle sobre ela era feito através da sociedade, simbolizada pela figura masculina. Esse controle era externado através dos comportamentos exigidos à mulher de forma que sua privação de liberdade não se limitasse aos muros das instituições prisionais, mas estivesse diretamente relacionado às convicções moralmente condenáveis (MENDES, 2014).

Foi a partir da diferenciação sexual que se construiu a separação entre masculino e feminino. Porém, essa divisão baseada em fatores biológicos nunca foi igualitária. Historicamente falando, o homem gradativamente se tornou a representação do ser humano, já a mulher passou a ser vista como o "desvio" ou o "outro" do homem, estipulando uma hierarquia entre os indivíduos baseada na separação do sexo (FERREIRA, 2007).

Essa hierarquização possibilitou a construção de papéis e comportamentos sociais lastreados na divisão de gênero, delimitando os espaços públicos (homens) e privados (mulheres) conforme a divisão sexual e atribuindo funções específicas e invioláveis a homens e mulheres (BARATTA, 1999, p.45).

A estrutura social passou a ser regida pela dominação masculina frente a submissão feminina, instituída através de controles formais e informais (GUARESCHI, 1999). Essas instituições sociais de controle, como, por exemplo, a igreja, família ou o Estado, passam a construir conceitos do que seja masculino e feminino, moldando e formando dentro da sociedade o que se pode entender como homem e mulher, bem como os papéis de cada um 
dentro do contexto social. Para Bourdieu, há uma construção de "hábitos" sociais que induz uma percepção de mundo lastreada nas práticas que os cercam ${ }^{4}$.

A partir desses hábitos a sociedade incorporou naturalmente estruturas e relações de poder que envolvem questões econômicas, raciais e de subordinação de gênero, onde o sexo masculino se apresenta como responsável pela construção e manutenção desse processo de dominação. (BOUDIEU, 2003, p.46).

A manutenção desse comportamento, a inexpressividade das mulheres nos espaços públicos e a "irrelevância" atribuída a suas práticas no ambiente doméstico, fizeram com que a criminologia, durante muito tempo, não se ocupasse com estudos específicos sobre o envolvimento da mulher com o mundo do crime. Com isso, sua participação no crime esteve sempre muito relacionado à criminalidade masculina - seja pela iniciação das mulheres no crime ou pela falta de estudos e dados específicos ao tema. Com a pouca exploração da criminalidade feminina acreditava-se que a participação da mulher fosse pequena e inexpressiva. Na contramão doesse entendimento, os estudos e relatórios sobre o sistema carcerário apontam para um aumento gradativo e significativo de mulheres envolvidas com o crime, principalmente, com o tráfico de drogas (FRINHANI, 2005).

Segundo Espinoza, um dos primeiros estudos sobre a criminalidade feminina foi elaborado por Cesare Lombroso e Giovanni Ferrero na obra La donna delinqüente. Neste livro, defendem que a mulher tem imobilidade e passividade particulares, determinadas fisiologicamente. Por isso, ela apresenta maior adaptabilidade e obedece mais à lei que os homens. No entanto, ela é potencialmente amoral, quer dizer, enganosa, fria, calculista, sedutora e malévola. (2004, p.55).

Essa visão também é compartilhada por Assis e Constantino (2001) quando dizem que as mulheres estão sujeitas a influências fisiológicas e que, por isso, são limitadas e só cometem crimes dentro dos espaços privados, uma vez que os espaços públicos pertencem aos homens. Corroborando com esse entendimento, Buglione (1998) chega a afirmar que a mulher estava destinada aos espaços privados, sendo também sua guardiã, em outras palavras, caberia à mulher a responsabilidade desses espaços, devendo se manter afastada de toda e quaisquer atividades privativas aos homens, entre elas o mundo do crime. Buglione afirma que a análise da criminalidade feminina sempre se limitou ao que se pode chamar de "delitos

4 "um sistema de disposições duráveis e transponíveis que, integrando todas as experiências passadas, funciona a cada momento como uma matriz de percepções, de apreciações e de ações - e torna possível a realização de tarefas infinitamente diferenciadas, graças às transferências analógicas de esquemas" (BOURDIEU, 1983, p.65). 
de gênero", como infanticídio (art. 123 Código Penal), aborto (art. 124 CP), homicídios passionais (art.121 CP), exposição ou abandono de recém-nascido para ocultar desonra própria (art. $134 \mathrm{CP}$ ), furto (art. $155 \mathrm{CP}$ ), além da ideia de que a conduta criminosa estivesse estritamente relacionada com os delitos dos companheiros ou maridos, ou seja, há poucos estudos, referências e políticas criminais direcionadas às mulheres (1998, p.8).

Para Lombroso, enquanto uma mulher tida como normal tem sua sexualidade voltada para a maternidade, fazendo com que seus filhos(as) e sua família sejam prioridades em sua vida, as criminosas agem exatamente ao contrário, não hesitando em abandonar e abrir mão do que pode ser mais sagrado - a maternidade - para se envolverem com o crime e a prostituição (LOMBROSO apud MENDES, 2012).

Outro fator utilizado como justificativa para a dupla punição da mulher é a desestruturação familiar. Como à mulher é atribuído o bom andamento do lar, sendo responsável pelos cuidados e criação dos filhos e até mesmo pelo sustento da família, ao se envolver com o crime e ser presa ela abandona afetiva e financeiramente seus filhos (as), conduzindo-os (as), direta ou indiretamente, para a criminalidade. Com isso, o dano social causado com a prisão da mulher é degradador e caberá ao Estado (e toda sociedade), através do direito penal, puni-la exemplarmente (BUGLIONE,1998).

Destarte, a criminologia voltada para a mulher só se inicia a partir do movimento feminista que trouxe novos paradigmas críticos do sistema penal, já que este era interpretado de maneira macrossociológica, adotando ideias do patriarcado e de gênero, sem verdadeiramente indagar as questões que levam a mulher a ser inserida no sistema de justiça criminal (CHERNICHARO, 2014).

Nesse sentido, Vera Andrade aponta que o feminismo foi de inegável importância para a construção de uma criminologia voltada para o feminino e não mais presa às ideias e saberes masculino. Diz a autora que o feminismo é um sujeito coletivo monumental que media a história entre um saber masculino onipresente - a criminologia - e um sujeito ausente - o feminino e sua dor - e ressignifica a relação entre ambos, aparecendo como um novo poder/saber de gênero, cujo impacto científico e político é sentido profundamente no campo da Criminologia, até então prisioneira do androcentrismo (ANDRADE, 2012. p.127).

Não só o discurso criminológico serviu para a manutenção da desigualdade de gênero. Ainda percebe-se na construção legislativa, nas práticas jurídico-penais e no senso comum, o tratamento preconceituoso e discriminatório e todo o julgamento moral sofrido por essas 
mulheres, principalmente as que cometem delitos, mantendo-se sempre presente e atuante a cultura da desigualdade de gênero.

Somado a isso, com o feminismo, foi necessário compreender a construção social dos gêneros e do processo de sujeição naturalizado pelas práticas sociais e jurídicas, relacionando e denunciando a parceria velada entre o Sistema de Justiça Criminal e os mecanismos de controle informais, através dos processos de criminalização e vitimização das mulheres de forma seletiva e estigmatizante, a partir de valores da cultura patriarcal como a "honestidade" sexual (MENDES, 2012).

\section{A MULHER E A MATERNIDADE}

A honestidade sexual da mulher sempre esteve diretamente relacionada à construção familiar, à maternidade e à continuidade da espécie, mantendo-se, como destaque, e sob a vigilância da construção histórica da humanidade. No período pré-histórico, por exemplo, a sociedade era formada pelo agrupamento de pessoas divididos por funções, habilidades e por gênero. Entre essas atribuições cabia à mulher, entre outras coisas, gerar. Assim os grupos se deslocavam e povoavam o mundo desenvolvendo identidades próprias e modo de viver que eram transmitidos de geração a geração. (STEARNS, 2013).

As identidades que formavam cada grupo tinham um traço em comum, o sistema patriarcal. A relação de superioridade era estabelecida através do matrimônio obrigatório e sem nenhuma necessidade de afeto ou prazer entre os conjugues. Essa união ocorria, principalmente, para que a mulher pudesse dar continuidade à linhagem. Caso a mulher não gerasse a aliança firmada poderia ser desfeita, pois, com a esterilidade ela não teria utilidade para o marido (COULANGES, 2004).

A civilização evoluiu, porém, a representação feminina não mudou muito, em alguns momentos até piorou. Esse comportamento social é evidenciado durante o período da Idade Média, onde reinou a misoginia, ou seja, a mulher era tratada como um ser diabólico. Os religiosos da época distorciam a criação para justificar a submissão feminina, pois, diziam que as mulheres eram impuras e tendenciosas ao pecado e prazeres carnais; eram vistas dessa maneira porque todas descendiam de Eva, a mãe e a culpada pela degeneração humana. Após um longo período de menosprezo às mulheres, a Igreja medieval construiu uma nova imagem e comportamento feminino para a sociedade. Assim, surge o ideal da mulher santa, a mãe 
exemplar, esposa devota, submissa e preservada dos prazeres da carne - do sexo (LEAL, 2012).

Badinter (1985) diz que essa nova imagem da mulher aos poucos foi absolvida por toda sociedade, principalmente pelos homens que passaram a enxergar a mulher como um ser fraco e impotente e não mais a figura de alguém maligno e diabólico. Essas mulheres submissas foram silenciadas durante séculos e obrigadas a desempenharem o único papel a elas permitido, o de esposa fértil e mãe devota. A maternidade era considerada símbolo de santidade, prosperidade e continuidade. (LEAL, 2012).

A instalação e manutenção do sistema patriarcal tinha um único objetivo, controlar as relações entre os gêneros e evitar que de alguma forma os "hábitos" sociais construídos deixassem de existir. Ao homem sempre coube exercer e preservar o domínio sob as mulheres; elas, insatisfeitas e infelizes, aceitavam sem contestação, afinal era algo posto desde os primórdios, portanto, incontestável. (STEARNS, 2013).

Seja nas culturas passadas ou ainda nos tempos modernos, a mulher não ocupava uma posição de destaque ou valorização. Elas não eram donas das próprias vidas, não podiam escolher seus "destinos", principalmente quando se tratava da maternidade (se estéril eram repudiadas), sempre foram totalmente ou parcialmente dependentes dos homens desde o dia em que nascessem (do pai ou irmão) ao dia que morressem (do marido ou filho). Não escolhiam seus maridos, não podiam se separar e, quando viúvas, nem sempre podiam opinar sobre um novo companheiro. Essa subserviência feminina é milenar e universal e se apresenta como a primeira forma de opressão e controle na história da humanidade (COULANGES, 2004).

Essa opressão se manifestava de várias formas e condutas. Seja por classificá-las como seres frágeis, sensíveis e dadas aos afetos, sentimentos tidos como "naturais" ou biológicos, seja por desconsiderarem seus papéis na sociedade, os estudos relacionados às mulheres têm sofrido influências da construção social, histórica e cultural. A ideia de que o corpo da mulher não lhe pertence e deve respeitar as "regras" de "boa conduta" tenta afirmar a equivocada construção social que definem, com base no biológico, o que a mulher pode ou não fazer, pode ou não ser e ter (DUARTE, 1998).

Nesse sentido, o caráter socialmente construído, em torno da maternidade, é ilustrado pela diversidade de significados que ela pode assumir dentro da sociedade. A maternidade não é apenas indício do desempenho de uma atividade biológica ou natural, ela se apresenta, 
também, como composição social e cultural. Assim, as relações sociais definem as categorias fundamentais de uma visão de mundo baseada em princípios sociais de divisão e oposição que são arbitrários. A diferença biológica é usada como forma de justificar as diferenças socialmente construídas. Dessa maneira, os fenômenos biológicos são vivenciados a partir da construção social e cultural vigente e as imposições socioculturais são tão enraizadas pelos "hábitos" que passam a ser percebidas como naturais (DUARTE, 1998).

Toda essa construção social do papel da mulher formou o simbolismo do movimento feminista no século passado. Esse movimento abarcou uma série de registros históricos, culturais e sociais vivenciados por séculos no lugar ocupado pela mulher e sua relação de gênero. Entre esses registros históricos do papel da mulher na sociedade, o feminismo aborda e questiona o conceito de maternidade e sua finalidade, desconstruindo o entendimento de que a maternidade seja uma mera forma de procriação e continuidade da espécie, baseada em perspectivas sociais, biológicas e psíquicas (REZENDE, 2016).

Com o movimento feminista há a luta pela cidadania, pela voz feminina, pelo empoderamento da mulher seja no ambiente público ou privado. Entre uma das questões abordadas pelo movimento foi a maternidade, como se apresentava no meio social, fazendo que seu conceito se conjugue pelo papel conquistado pela mulher na sociedade, por questões sociais, e não o imposto por gerações, questões biológicas (COSTA, 2001).

A partir do século XVIII, uma nova imagem de mãe começou a ser definida e foi aperfeiçoada durante os dois séculos seguintes. A maternidade no século XIX passa a ser vista como algo a ser cultuado e a segundo essa compreensão, a mulher e seu filho passam a ocupar um espaço de honra na sociedade. Com as mudanças sócias e política, a mulher passa a ser responsável pelos cuidados e educação dos filhos(as) e o que antes era uma função meramente biológica adquire status de função social (REZENDE, 2016).

Ao se apresentar, como função social, a maternidade passa a auxiliar na divisão do trabalho no âmbito familiar. Cabe a mulher a responsabilidade pela estruturação do lar e o cuidado dos filhos (as). Cabe a ela ser mãe. Essa distinção de papéis entre os gêneros masculino e feminino contribuiu para aumentar a diferença entre os sexos, revelando que a própria família produz mulheres para serem mães e sustenta o preconceito (CHODOROW, 2002).

Em uma perspectiva social, a mulher nasce para ser mãe. Todo o seu corpo é biologicamente preparado para o momento de gerar e perpetuar a espécie. Também se acredita 
que a mulher só é plena quando passa pela maternidade e gera outro ser (BEAUVOIR, 2009). Nessa compreensão social do que é ser pleno, se induz a acreditar que a mulher só se constituirá ou só efetivará o seu objetivo maior de vida, quando passar pela maternidade e somente alcançará um status maior na sociedade, quando for uma boa mãe. A maternidade é vivida não apenas como processo corporal, mas como a atribuição de status superior à mulher - em relação às mulheres sem filhos (DUARTE, 1998)

Esse comportamento garante a sobrevivência da espécie, a manutenção das desigualdades e o preconceito, incutindo na mulher a obrigatoriedade da maternidade, fazendo com que toda exceção à regra se apresente como algo patológico. A mulher que não gera não se realiza; a mãe indiferente é um desacato, é um ser anormal e desumana por natureza (BADINTER, 1985).

É fato que a especificidade do corpo feminino tem sido usada como forma de marcar sua inserção na realidade social. A concepção de saúde da mulher está associada à sua fertilidade e a maternidade é percebida como manifestação de saúde e satisfação. Entretanto, as experiências vividas na gravidez, no parto e amamentação podem deixar marcas, no corpo e na alma das mulheres. Na construção social tida como ideal para as relações, as mulheres que são mães não são descritas como frágeis; pelo contrário, elas são tidas como a força responsável pelo bom andamento da família e filhos (a), para isso, demonstram a valentia necessária para enfrentar qualquer coisa que ameace essa estrutura. Isso evidencia que as especificidades do corpo feminino foram tomadas para determinar sua característica, posição, status e função social (DUARTE, 1998).

$\mathrm{Na}$ contemporaneidade as ideologias sociais e culturas ainda responsabilizam a mulher pelo cuidado do lar, pelo exercício pleno da maternidade e pela submissão ao homem. Falsamente acredita-se que a maternidade é um destino do qual a mulher não pode fugir, devendo, portanto, submeter-se, pois é a única que tem o corpo e estrutura biológica para a reprodução e continuidade da raça humana. A maternidade é entendida como algo sublime e venerado, não sendo admitido nenhuma forma de "mácula". Não se pode correr do destino biologicamente traçado, como também não se pode ficar ilesa a sua negação (REZENDE, 2016).

Ainda hoje espera-se que a mulher realize sua missão (maternidade) com esmero; que enquanto mulher e mãe aceite passar por essa fase com tranquilidade e equilíbrio, e que se 
sinta enaltecida por gerar outro ser, mesmo que durante a gravidez experimente sentimentos antagônicos e traumáticos (BEAUVOIR, 2009).

Ao considerar a composição biopsicossocial da maternidade, é possível perceber sua complexidade e entender que ela não é obrigação, devendo ser algo desejado e planejado. Vale ressaltar que hoje luta-se para que a maternidade não seja determinante no conceito de mulher, que ela apenas complemente e caracterize uma das muitas funções que a mulher pode exercer. Se a gravidez não define a mulher também não pode ser usada como balança de moralidade social para culpar, julgar e condená-la (REZENDE, 2016).

\section{A MULHER, A MATERNIDADE E O CÁRCERE}

Muitos caminhos levam ao cárcere, mas, para as mulheres eles se resumem a basicamente um: o tráfico de drogas. $\mathrm{O}$ aumento do encarceramento feminino não é privilégio do Brasil. Na última década, esse crescimento foi constatado, não só na América Latina, como em todo mundo. Os dados apontam como principal motivo desse aumento uma política criminal de guerra às drogas proibicionista e repressiva, que obedece a uma lógica violadora de garantias individuais e de princípios constitucionais, como a presunção de inocência e a proporcionalidade das penas, dentre outros. (CHERNICHARO, 2014).

Luciana Boiteux (2009) sustenta que o endurecimento da legislação e sua aplicabilidade tem, como base, o discurso do inimigo social como alvo principal do direito penal, no caso do tráfico de drogas os traficantes e seus "comparsas". Neste sentido, o medo e a insegurança sustentados pela presença do inimigo, transforma o sujeito em um ser sem rosto, forma ou direitos. Esse entendimento se estende também às mulheres, inclusive as mães e puérperas, que além de inimigas sociais são vistas como "desertoras" de uma vida segura (o lar) e de privilégios inegociáveis (a maternidade).

É importante salientar que o sistema penal constrói sua relação com o feminino (reafirmando e reproduzindo) a partir das desigualdades de gênero, atuando desde a fundamentação e funcionamento até a aplicação das normas por agentes que se pretendem neutros. Com isso, constata-se que as estruturas de poder, nesse caso o Direito, estão sustentadas em características masculinas - força, racionalidade, objetividade - em contraposição às femininas - emoção, fragilidade, subjetividade. Essas características reafirmam a hierarquia social imposta onde as masculinas são superiores à feminina e mais 
importantes, tanto para o Direito, como para o contexto social vigente (CHERNICHARO, 2014).

Essas definições e classificações adotadas proporcionam a manutenção de um poder patriarcal e de um controle social informal que levam à criação de estereótipos sociais, como por exemplo os papéis reprodutivos assegurados às mulheres. Ao pensar e agir, a partir da lógica masculina, o Direito compactua com a reprodução da ordem estabelecida e busca controlar as condutas humanas e, entre elas, as condutas sexuais. Dessa forma, a mulher se apresenta como a guardiã do lar e como a boa mãe, cabendo ao direito penal garantir que sua integridade e honestidade sejam protegidas para que a violação desse status não venha a interferir no seu papel social de reprodutora e garantidora da linha sucessória familiar (CHERNICHARO, 2014).

Quando a mulher perde sua liberdade de ir e vir, entre os muros dos presídios, é difícil ficar calada e ver emergir os "monstros" desumanos; é difícil acordar atenta quando a amarga noite se aguenta; é difícil viver de pecados e venenos inventados. O presídio é um pedaço de mundo que embriaga para se esquecer do resto do mundo; é o deserto contínuo que assume a forma e a cor da dor.

O fracasso histórico e atual das prisões não sustenta o "mito do bom presídio", pelo contrário, ele reforça o compromisso crítico para que haja uma minimização dos efeitos perniciosos do confinamento, pois, segundo Lemgruber, a prisão funciona no sentido de aviltar e estigmatizar para sempre os que por ela passam e, na medida em que não se visualiza sua extinção num futuro próximo, há que se lutar para que sua influência se torne menos perniciosa. E, por fim, se alternativas à prisão existem, urge aumentar sua abrangência e exigir sua aplicação (1999, p. 162).

O sofrimento durante o cumprimento da pena privativa de liberdade é desumano. A gravidez no cárcere é sempre uma gravidez de risco, pois o presídio é sempre um lugar insalubre, inapropriado e inadequado, seja durante o período da gestação ou de amamentação. São poucas as instituições prisionais que prestam assistência adequada às mulheres grávidas e que, após o parto, podem disponibilizar estrutura física para que a mãe fique com a criança durante o período assegurado por lei.

A legislação vigente garante à mulher o direito de ter assistência à saúde, principalmente durante a gravidez, sendo-lhe ofertado um pré-natal adequado. A Lei no 11.942 de 2009, por exemplo, em seu artigo 14, $\S 3^{\circ}$, estabelece que "será assegurado 
acompanhamento médico à mulher, principalmente no pré-natal e no pós-parto, extensivo ao recém-nascido". E em seu artigo $83, \S 2^{\circ}$ complementa dizendo que: "os estabelecimentos penais destinados à mulher serão dotados de berçário, onde as condenadas possam cuidar de seus filhos, inclusive amamentá-los no mínimo, até 06 (seis) meses de idade" (BRASIL, 2009).

Além disso, segundo a Organização Mundial da Saúde (OMS) e o Ministério da Saúde, a amamentação exclusiva deve ser ofertada à criança, pelo menos nos seis primeiros meses de vida, pois só assim ela terá garantido importantes fontes de nutrientes, fundamentais para seu bom desenvolvimento. Depois dos seis primeiros meses de vida, deverão ser introduzidos outros tipos de alimentos, entretanto, isso não exclui a continuidade da amamentação, que deverá permanecer, preferencialmente, até os dois anos de idade.

Impedir a amamentação é uma violação de direito, não só da mãe, como também do bebê. Em outras palavras, negar esse direito é transferir à criança o "castigo" da pena de sua mãe, algo vedado pela Constituição Federal de 88 que preceitua, em seu art. 5, inciso XLV, que nenhuma pena deve passar da pessoa do condenado. Além disso, não se pode deixar de observar o descrito nos incisos III e XLVII do art. $5^{\circ}$ da Constituição que, em consonância com a Convenção contra a Tortura de 1984 (Decreto 40/1991) vedam penas e tratamentos cruéis, desumanas ou degradantes. Em momento algum, pode-se aceitar o fato da extensão da pena a pessoa da criança.

A Constituição brasileira, em seu art. 5, inciso 1, também garante que: "às presidiárias, serão asseguradas condições para que possam permanecer com seus filhos durante o período de amamentação". Outra lei, o Estatuto da Criança e do Adolescente (ECA), em seu art. 9, afirma que: "o poder público, as instituições e os empregadores propiciarão condições adequadas ao aleitamento materno, inclusive, aos filhos de mães submetidas à medida privativa de liberdade". Em termos de legislação, ainda deve ser levado em consideração o princípio da proteção integral à criança e as regras do Estatuto da Primeira Infância (Lei 13.257/2016), que alterou o Estatuto da Criança e do Adolescente e o Código de Processo Penal.

Somando aos dispositivos legais internos, em 2010 a Assembleia Geral da ONU (Organização das Nações Unidas) aprovou as Regras das Nações Unidas para o Tratamento de 
Mulheres Presas e Medidas não Privativas de Liberdade para Mulheres Infratoras, a conhecida Regras de Bangkok ${ }^{5}$.

Vale destacar as Regras 57 e 58 de Bangkok, que trata sobre medidas não privativas de liberdade para mulheres autoras de crimes:

Regra 57 As provisões das Regras de Tóquio deverão orientar o desenvolvimento e a implementação de respostas adequadas às mulheres infratoras. Deverão ser desenvolvidas, dentro do sistema jurídico do Estado membro, opções específicas para mulheres de medidas despenalizadoras e alternativas à prisão e à prisão cautelar, considerando o histórico de vitimização de diversas mulheres infratoras e suas responsabilidades de cuidado (2010).

Regra 58 Considerando as provisões da regra 2.3 das Regras de Tóquio, mulheres infratoras não deverão ser separadas de suas famílias e comunidades sem que se considere devidamente a sua história e laços familiares. Formas alternativas de lidar com mulheres infratoras, tais como medidas despenalizadoras e alternativas à prisão, inclusive à prisão cautelar, deverão ser empregadas sempre que apropriado e possível (ONU, 2010).

Portanto, não há o que se falar em transmissão do peso da pena, em impedimentos legais para a gestação e amamentação durante o período em que a mulher estiver presa. $\mathrm{Na}$ verdade, o que há é um descaso do sistema prisional com as mulheres no ciclo gravídico puerperal e durante a amamentação, períodos em que são desconsideradas todas as dificuldades e especificidades vivenciadas por elas, deixando bem claro o abismo existente entre o que assegura os dispositivos legais e a amarga realidade.

Esse momento da vida da mulher gera sentimentos antagônicos. O prazer da maternidade nem sempre supera seus borrões. São incontáveis mudanças que precisam ser administradas e vencidas durante nove meses. Para muitas, esse é o momento em que elas estão presas nos elos de uma só cadeia. Mãe e filho(a): duas histórias em um só corpo.

A medicina diz que, durante a gestação, o feto absorve todas as emoções vivenciadas pela mãe. Com isso, deve-se levar em consideração que a vida em formação no ventre da interna depende, única e exclusivamente, do seu bem-estar. Isso significa dizer que, embora

5 "9. ao sentenciar ou decidir medidas cautelares a mulheres grávidas ou pessoa que seja fonte primária ou única de cuidado de uma criança, medidas não privativas de liberdade devem ser preferíveis quando possível e apropriado, e considerar impor penas privativas de liberdade a casos de crimes graves ou violentos" (ONU,2010).

Rev. de Criminologias e Politicas Criminais | e-ISSN: 2526-0065 | Porto Alegre | v. 4 | n. 2 | p. 21 - 44 | Jul/Dez. 2018 
seja cabível a aplicação da pena privativa de liberdade, esta não deve ter peso maior do que a vida intrauterina sendo gerada. No caso da presidiária grávida isso se potencializa, pois, como disse Armelin (2010): “qualquer pessoa que tem contato com uma prisão sofrerá alguma mudança, e assim, devemos incluir os filhos das mulheres encarceradas"- mesmo ainda no ventre.

No Brasil, em sua grande maioria, as prisões femininas são escuras, fétidas, encardidas e superlotadas. Dormir no chão, fazendo revezamento para ficar um pouco mais confortável, é praticamente a regra. Os banheiros exalam mau cheiro, a higiene nem sempre é a mais desejável, os espaços para banho de sol são inadequados e não existe a mínima estrutura para acomodar uma criança. Por tudo isso, nos presídios, não há espaço para sonhos, ideais, muito menos para maternidade. Livres, as mulheres podem gerar vidas; presas, elas procriam desilusões. Isso é comprovado na ausência total ou parcial de laços afetivos construídos com os filhos(as); muito, também, fruto do abandono que essas mulheres sofrem quando estão presas. Já que as famílias, na maioria das vezes, se afastam ou se isolam por completo dessas mulheres, seja no período gestacional ou não, deixando-as mais predispostas a perturbações psicológicas oriundas da carência afetiva por separação e abandono, instabilidade e desestruturação familiar (BISPO, 2016).

Convém destacar que, mesmo tendo consciência das regras de conduta e disciplina dos presídios (seja por parte das detentas ou mesmo dos (as) agentes) que quase sempre atingem diretamente as crianças, são poucos os magistrados que se sensibilizam e concedem prisão domiciliar às mulheres grávidas ou com crianças. Muitos chegam a justificar a negativa, de modo expresso ou subentendido, pelo fato da mulher ter "escolhido" o mundo do crime, e que, portanto, deve arcar com as penalidades de tal escolha, entre elas, a "prisão" de seu filho(a). Em outras palavras, essa escolha deve gerar uma tripla punição da mulher presa: a do crime, a de ser mulher e a de mãe que desconsiderou o "milagre" da maternidade ao escolher ingressar na marginalidade. Portanto, caberá à justiça puni-la adequadamente para que esta retome a consciência um dia perdida.

Ao falar da prisão como meio de controle da mulher, Aline Pancieri e Luciana Boiteux(2017) afirmam que no sistema prisional é com a prisão preventiva, que aparece como regra, que esse controle se estabelece, principalmente nos crimes de tráfico de drogas. Conforme a Constituição Federal e a Lei n. 12.403/11, essa prisão deveria ser a exceção e não 
regra. Entretanto, seu uso aparece de forma corriqueira e banal, "funcionando como uma verdadeira antecipação da pena. A regra é prender antes de condenar”.

A Lei n. 12.403/11 e a de n 13.257/16 trouxeram importantes mudanças, inclusive com a alteração do artigo 318 do Código de Processo Penal, garantindo às mães de crianças de até 12 anos incompletos ou mulheres grávidas, o direito de cumprir prisão provisória em regime domiciliar, porém, essa alteração ainda é inobservada quando o assunto é a prisão das mulheres, mesmo que a Lei n. 12.403/11 diga que a custódia cautelar é medida excepcional, havendo outras alternativas à prisão preventiva. Neste sentido já se posicionou o STF, no HC n. 94.1579: "a privação cautelar da liberdade somente se legitima quando existirem razões reais de necessidade, e quanto as medidas cautelares não forem efetivamente adequadas" (PANCIERI; BOITEUX, 2017).

Ainda nessa linha da prisão ser a última medida a ser adotada, as autoras salientam que a Lei n. 13.257/16 aumentou as possibilidades da prisão domiciliar, que antes estavam restritas às grávidas a partir do sétimo mês de gestação, ou em casos de gravidez de risco. A partir dessa lei, que alterou o conteúdo do artigo 318 do CPP, a prisão domiciliar pode ser estendida às grávidas a qualquer tempo da gestação, bem como às mães com filhos de até 12 anos de idade. Desta forma, as medidas cautelares em geral, inclusive a prisão domiciliar, são direitos das acusadas, devendo sempre ser priorizadas frente a prisão preventiva (PANCIERI; BOITEUX, 2017).

Mas, infelizmente, essas garantias processuais são utilizadas inversamente proporcional à lógica legal, em outras palavras, a prisão domiciliar, como as demais medidas cautelares, não são prioridades para assegurar os direitos da mulher em situação de maternidade. Este posicionamento, apesar de inconstitucional, é o que vigora na maior parte das decisões judiciais, e se relaciona diretamente à concepção errônea de que cabe à defesa demonstrar que a prisão não é necessária (PANCIERI; BOITEUX, 2017).

Fatos recentes trouxeram a questão da prisão domiciliar e o direito das mulheres grávidas ou com filhos de até 12 anos à tona (Lei 13.257/16). Em março de 2017, a ministra do Superior Tribunal de Justiça - STJ Maria Thereza de Assis Moura concedeu liminar em Habeas Corpus para que a advogada Adriana Ancelmo, mulher do ex-governador do Rio de Janeiro, Sérgio Cabral (PMDB), ficasse em prisão domiciliar. A decisão levou em consideração o fato de que ela tem filhos de 11 e 14 anos e que seu marido também estava preso, o que dificultava o cuidado e criação dos filhos (HC 392.806). (STJ, 2017) 
Esse fato (re)acendeu a discussão sobre a prisão de mulheres grávidas ou com filhos menores de 12 anos, pois, para muitos (inclusive magistrados e promotores), mulheres nessa situação devem permanecer presas, já que a conversão para prisão domiciliar poderia caracterizar impunidade. Sem adentrar no mérito da questão, o HC concedido pelo STJ contribuiu para que a lei fosse cumprida interferindo em outras decisões, uma vez que a prisão domiciliar nesses casos dependia, unicamente, da interpretação - e (pre)conceito - do juiz(a), do caso.

Segundo dados do Conselho Nacional de Justiça, 622 mulheres presas estão grávidas ou em fase de amamentação. Colaborando com esses dados do IBCCRIM - Instituto Brasileiro de Ciências Criminais - em conjunto com outras entidades - fez um levantamento de dados em 22 Estados e concluiu que 4.560 mulheres grávidas ou com filhos de até 12 anos estão presas provisoriamente. O que reafirma o entendimento de que a prisão é sempre a primeira opção, mesmo que a pessoa presa seja mulher com filhos pequenos ou grávidas (LIMA, 2018).

Outro fato ocorreu em fevereiro do corrente ano com uma gestante presa um dia antes de dar a luz e mantida na cadeia com o bebê recém-nascido. Jéssica Monteiro, de 24 anos, e o marido Oziel Gomes da Silva, de 48 anos, foram detidos por tráfico de drogas. Ela foi autuada em flagrante com cerca de 90 gramas de maconha e entrou em trabalho de parto logo após a prisão. Réu primária, na audiência de custódia não pode comparecer - estava no hospital parindo - e foi representada por seu advogado, mesmo assim o juiz responsável pelo caso decidiu manter a prisão dela. Mãe de uma outra criança de 03 anos, após o nascimento do seu bebê Jéssica foi escoltada de volta para a carceragem do Distrito Policial, no Brás, em São Paulo. A cela para a qual Jéssica e seu filho voltaram possuía cerca de dois metros quadrados, estava suja, com mau cheiro, tinha uma espuma no chão com alguns cobertores. Após dois dias nesse lugar foram transferidos para uma penitenciária com espaço para mães de recémnascido (CARTA CAPITAL, 2018).

Em janeiro desse ano, a presidente do Superior Tribunal de Justiça (STJ), Laurita Vaz, negou habeas corpus à mãe de uma criança de um mês de vida, impedindo-a de cumprir pena domiciliar. A mãe havia sido presa com $8,5 \mathrm{~g}$ de maconha encontrada dentro de um bolo que ela levava ao marido na prisão. Na decisão, Vaz afirmou que "a simples existência de filhos menores não enseja a concessão automática da benesse (da prisão domiciliar) " (IDOETA, 2018). 
Com o caso Jéssica e o "susto" social - como se esse fosse um fato isolado e que nunca tivesse acontecido antes - o Supremo Tribunal Federal - STF, votou o habeas corpus coletivo, O recurso interposto em maio de 2017 pelo CADHu, o Coletivo de Advocacia em Direitos Humanos. Esse habeas corpus traz à tona o debate sobre a impunidade no Brasil e a situação das mulheres encarceradas - a maior parte delas negra, pobre e sem acesso aos direitos. (LIMA, 2018).

Por quatro votos a um, a Segunda Turma da corte do STF, acatou o habeas corpus coletivo em nome das detentas e de seus filhos, aceitando o argumento de que confinar mulheres grávidas em estabelecimentos prisionais precários, subtraindo-lhes o acesso a programas de saúde pré-natais, assistência regular no parto e pós-parto, e ainda privando as crianças de condições adequadas a seu desenvolvimento, constitui tratamento desumano, cruel e degradante (IDOETA, 2018).

Ao votar pela aceitação do habeas corpus, o Ministro Lewandowski, relator do caso, citou a "degradação do sistema prisional brasileiro" e afirmou que o modelo atual transfere a pena da mãe para as crianças. Além disso, a pedido de Gilmar Mendes, a prisão domiciliar será estendida também a mães de filhos com deficiência física ou mental, de qualquer idade (IDOETA, 2018).

Essa é uma decisão importantíssima e histórica, por ter sido um instrumento usado para uma coletividade delimitada, mas não nominada. E por ter o efeito de mudar "o foco" da lei de lugar. Pois hoje o objetivo é o aprisionamento em massa, não na lei, mas, na prática judiciária e a liberdade como última saída. Com essa decisão o STF, reconhece que toda gravidez no cárcere é uma gravidez de risco, traz perigo para mãe e bebê, pois nos espaços dos presídios não há como receber mulheres grávidas, de lactantes e de crianças. E, quando as crianças ficam em casa com outro familiar e a mãe em prisão cautelar fica na prisão, há uma segregação entre mãe e filho. A gravidez e o exercício de maternidade na prisão não são possíveis, além de agravar os problemas de saúde e psíquicos das mulheres e todos que a cercam, quando a cercam (LIMA, 2018).

A partir de agora, nas prisões de mulheres gestantes, puérperas ou com filhos(as) pequenos, a partir dessa decisão, juízes e promotores vão ter que ter como foco de ação o que prevê a lei e não mais o que seus (pre)conceitos entendem como o melhor a fazer (LIMA, 2018). 
Enfim, mesmo nesse cenário de "castigo" e "dores de forma e cor", ainda resta um fio de esperança de que "talvez o mundo não seja tão pequeno, nem a vida um fato consumado"; de que a ressocialização, assim como a vivência plena da maternidade, não seja um fato utópico, uma vez que, de uma utopia morta só saltam os reflexos da herança do sistema prisional que envenena e mata seus herdeiros, que os fazem tragar a dor e engolir a labuta da mentira, para (re)inventá-los em pecados.

\section{CONSIDERAÇÕES FINAIS}

Os pecados inventados limitou a mulher aos espaços privados. As mulheres que se inseriam na dinâmica da economia e política eram mais sujeitas aos processos de criminalização e encarceramento. Com isso, o controle sobre elas se dava através das instituições sociais sendo realizado de diferentes formas nos períodos históricos. Contribuindo com essas instituições o sistema penal, representado pelo Estado, age sobre a vida das mulheres de diversas maneiras, inclusive, quando prende e/ou mata seus maridos, filhos, familiares.

Para um Estado de direito que precisa afirmar seu poder na legitimidade das políticas penais, as mazelas se apresentam nas prisões desenfreadas das mulheres, as mais vulneráveis na dinâmica do crime. Essas mulheres são alvo fácil da criminalização e sofrem as consequências das condições estruturais do sistema social que opta por um sistema penal arcaico e ultrapassado, em vez de serem devidamente atendidas com serviços sociais e políticas públicas, apresentando, dessa forma, as colunas estruturais de um Estado Penal e não de um Estado Democrático de Direito.

A compreensão da sociedade como uma estrutura patriarcal e capitalista é fundamental para uma criminologia crítica e para o aperfeiçoamento do movimento feminista que luta contra um sistema de justiça que atua na vida das mulheres. É importante entender as peculiaridades do encarceramento feminino para que possamos romper com o aumento desenfreado dos aprisionamentos das mulheres. A invisibilidade sobre o tema tem ampliado um recorte de classe, raça e gênero que criminaliza e encarcera, impedindo que movimentos sociais feministas e de direitos humanos lutem por políticas públicas direcionadas a um sistema prisional igualitário e que atenda as necessidades das mulheres. 
É fato que a maioria das mulheres presas estão envolvidas com o tráfico de drogas. Esse envolvimento, normalmente, se dá pelo companheiro e com a finalidade de manter a casa e impedir a morte de todos. Entretanto, mesmo observando que não só o crime de tráfico de drogas leva ao aprisionamento das mulheres, é preciso perceber que existe uma relação direta entre a necessidade de controle - urbano, econômico e moral - e criminalização, obedecendo a demanda por ordem do momento histórico. Em outras palavras, nos crimes praticados por mulheres há sempre um comando moral por trás de sua condenação e aprisionamento.

Diante deste cenário do sistema prisional é importante que se problematize e questione as estruturas que encarceram mulheres, a partir das teorias da criminologia crítica e do feminismo. A criminologia, para que se compreenda como se articula o sistema de justiça na sociedade machista e o feminismo, para que a construção do conhecimento acerca de como os mecanismos de uma justiça patriarcal agem sobre a vida das mulheres e ambos, para que se mude o foco do conhecimento historicamente construído através da perspectiva masculina.

Entretanto, essa é uma visão que ainda encontra muita resistência, deixando evidente a dificuldade na assimilação das demandas feministas e o quanto é necessária a consolidação de uma criminologia que desconstrua o caráter sexista e androcêntrico das ciências penais, e dê visibilidade às relações de poder baseadas no gênero.

Nesse sentido, o habeas corpus coletivo concedido pelo STF (HC 143641) reafirma a necessidade de mudanças, tanto na estrutura do sistema prisional, como no entendimento social e institucional sobre a aplicabilidade das penas das mulheres encarceradas. Já que o sistema penal contemporâneo reafirma a desumanidade com que são tratadas essas mulheres e as restringem de direitos básicos. As crianças nascidas neste contexto, quando ficam com suas mães, tornam-se vulneráveis a doenças e atrasos no desenvolvimento, devido às condições precárias do ambiente prisional e, se forem afastadas das mães logo após o parto, perdem por não desfrutarem do vínculo materno e por não serem amamentadas, como lhes seria de direito.

Portanto, deve-se primar pelo cumprimento dos instrumentos legais, pela educação e saúde das gestantes encarceradas, pois a negação deles reflete diretamente no retorno social da violência e marginalização, quer das mulheres, quer dos seus filhos. É preciso aceitar que respeitar a dignidade das mulheres gestantes encarceradas não é uma questão de favor, mas sim de direito e justiça. 


\section{REFERÊNCIAS}

ANDRADE, Vera Regina Pereira de. Pelas Mãos da Criminologia: o controle penal para além da (des)ilusão. Rio de Janeiro: Revan. 2012.

BADINTER, E. Um amor conquistado: o mito do amor materno. Rio de Janeiro: Nova Fronteira, 1985.

BARATTA, Alessandro. O paradigma do gênero: da questão criminal à questão humana. In: CAMPOS, Carmen (Org.). Criminologia e Feminismo. Porto Alegre: Sulina, 1999.

BEAUVOIR, Simone. O segundo sexo. 2.ed. Rio de Janeiro: Nova Fronteira, 2009.

BOITEUX, Luciana. WIECKO, Ela. (Coord). Tráfico de Drogas e Constituição: Um estudo Jurídico-Social do Art. 33 da Lei de Drogas Diante dos Princípios ConstitucionaisPenais. Brasília: Ministério da Justiça. Série Pensando o Direito, vol. 1, 2009.

BOURDIEU, Pierre. A dominação Masculina. 3. ed. Rio de Janeiro: Bertrand Brasil, 2003.

BRASIL, Ministério da Justiça. INFOPEN (2017). Levantamento Nacional de Informações Penitenciárias Atualização - Junho de 2016. Organização, Thandara Santos. Colaboração, Marlene Inês da Rosa [et.al.]. Brasília. Ministério da Justiça e Segurança Pública. Departamento Penitenciário Nacional, 2017. 65p. Disponível em: http://www.justica.gov.br/news/ha-726-712-pessoas-presas-nobrasil/relatorio_2016_junho.pdf Acesso em: 20 de julho de 2018.

Ministério da Justiça - Departamento Penitenciário Nacional - Levantamento Nacional de Informações Penitenciárias - INFOPEN MULHERES, 2018. Disponível em http://depen.gov.br/DEPEN/depen/sisdepen/infopen-mulheres/infopenmulheres_arte_07-0318.pdf Acesso em: 20 julho 2018.

BRASIL. Lei $\mathbf{n}^{\mathbf{0}}$ 8.069, de 13 de julho de 1990. Dispõe sobre o Estatuto da Criança e do Adolescente e dá outras providências. Diário oficial da união. 13 de julho de 1990. Disponível em http://www.planalto.gov.br/Ccivil_03/leis/L8069.htm Acesso em: 20.07.2018.

BRASIL. Lei $\mathbf{n}^{\mathbf{0}} \mathbf{1 3 . 2 5 7}$ de 08 de março de 2016. Dispõe sobre as políticas públicas para a primeira infância. Disponível em: http://www.planalto.gov.br/ccivil_03/_ato20152018/2016/lei/113257.htm Acesso em 19.07. 2018

BRASIL. Decreto $\mathbf{n}^{\mathbf{0} 40}$ de 15 de fevereiro de 1991. Promulga a Convenção Contra a Tortura e Outros Tratamentos ou Penas Cruéis, Desumanos ou Degradantes. Disponível em: http://www.planalto.gov.br/ccivil_03/decreto/1990-1994/D0040.htm Acesso em: 19.07.2018.

BRASIL. Lei no 11.942, de 28 de maio de 2009. Dá nova redação aos arts. 14, 83 e 89 da lei 7.210, de 11 de julho de 1984. Lei de Execução Penal, para assegurar as mães presas e aos recém-nascidos condições mínimas de assistência. Brasília (DF). Disponível em http://www.planalto.gov.br/ccivil_03/_ato2007-2010/2009/lei/111942.htm Acesso em: 19.07.2018.

BRASIL. Constituição (1988). Constituição da República Federativa do Brasil. Brasília, DF: Senado; $1988 . \quad$ Disponível em: https://www2.senado.leg.br/bdsf/bitstream/handle/id/518231/CF88_Livro_EC91_2016.pdf Acesso em: 19.07.2018 
BRASIL. Lei $\mathbf{n}^{\mathbf{0}}$ 10.792, de 01 de dezembro de 2003. Altera a Lei $\mathrm{n}^{\mathrm{o}} 7.210$, de 11 de junho de 1984 - Lei de Execução Penal e o Decreto Lei no 3.689 de 3 de outubro de 1941 - Código de Processo Penal e dá outras providências. Disponível em http://www.planalto.gov.br/ccivil_03/leis/2003/L10.792.htm Acesso em 20.07.18

BRASIL. Lei $\mathbf{n}^{\mathbf{0}} \mathbf{1 2 . 4 0 3}$ de 4 de maio de 2011. Altera dispositivos do Decreto-Lei $\mathrm{n}^{\circ} 3.689$, de 3 de outubro de 1941 - Código de Processo Penal, relativos à prisão processual, fiança, liberdade provisória, demais medidas cautelares, e dá outras providências. Disponível em: http://www.planalto.gov.br/ccivil_03/_ato2011-2014/2011/lei/112403.htm._Acesso em 20.07.18.

BUGLIONE, Samantha. A face feminina da execução penal. Direito \& Justiça. Revista da Faculdade de Direito da Pontifícia Universidade Católica do Rio Grande do Sul, Vol. 19, ano XX, 1998.

CARTA CAPITAL. Por decisão judicial, bebê de 3 dias está detido em cela de 2 metros com a mãe em SP. Disponível em: http://justificando.cartacapital.com.br/2018/02/14/pordecisao-judicial-bebe-de-3-dias-esta-detido-em-cela-de-2-metros-com-mae-em-sp/ . Acesso em:20.07.2018.

CHERNICHARO, Luciana Peluzio. Sobre mulheres e prisões: seletividade de gênero e crime de tráfico de drogas no Brasil. Dissertação de Mestrado defendida no Programa de PósGraduação em Direito da Universidade Federal do Rio de Janeiro, 2014. Disponível em: http://www.neip.info/upd_blob/0001/1565.pdf Acesso em: 19.07.2018.

CHODOROW, N. Psicanálise da maternidade: uma crítica a Freud a partir da mulher. 2. ed. Rio de Janeiro: Record: Rosa dos Tempos, 2002.

COSTA, L. C. Gênero: uma questão feminina? Núcleo de Pesquisa Universidade Estadual de Ponta Grossa. Disponível em: http://www.uepg.br/nupes/genero.htm Acesso em: 19 fev. 2018.

COULANGES, F. de. A cidade antiga. Rio de Janeiro: Ediouro, 2004.

DUARTE, LFD., and LEAL, OF. Doença, sofrimento, perturbação: perspectivas etnográficas . Rio de Janeiro: FIOCRUZ, 1998.

ESPINOZA, Olga. Mulher Encarcerada em Face do Poder Punitivo. São Paulo; IBCBRIM, 2004.

FERREIRA, Maria Luísa Ribeira. A mulher como o "outro": a filosofia e a identidade feminina. Revista da Faculdade de Letras da Universidade do Porto. v.23-24, p.139-153, 2007 .

FRINHANI, Fernanda M D. Mulheres encarceradas e espaço prisional: Uma análise de representações sociais. Psicologia: Teoria e Prática, 2005, 7(1): 61-79.

GUARESCHI, Pedrinho A. Sociologia crítica: alternativas de mudança. $46^{\mathrm{a}}$ Ed. Porto Alegre: EDPUCCRS, 1999. p. 91.

HARTMANN, Heidi. Un matrimonio mal avenido: hacia uma unión más progressiva entre marxismo y feminismo. Papers de la Fundación/88. Fundació Rafael Campalans. 
Disponível em http://www.fcampalans.cat/uploads/publicacions/pdf/88.pdf Acesso em 20.07.18

IDOETA, Paula Adamo - BBC Brasil. STF decide que grávidas e mães presas provisórias podem ir para casa. Disponível em: http://www.bbc.com/portuguese/brasil-43079116 Acesso em: 20.07.2018.

LEAL, L. S. M. As várias faces da mulher no medievo. Linguagem, educação e memória. Mato Grosso do Sul, v.03, p. 01-22, nov. 2012. Disponível em: http://www.uems.br/lem/EDICOES/03/Arquivos/larissaleal.pdf Acesso em: 19.07.2018.

LEMGRUBER, Julita. Cemitério dos vivos: análise sociológica de uma prisão de mulheres. 2. ${ }^{a}$ ed., Rio de Janeiro: Forense, 1999.

LIMA, Juliana Domingos de. STF aprova habeas corpus coletivo para mães. Qual o impacto da decisão. Disponível em: https://www.nexojornal.com.br/expresso/2018/02/21/STF-aprova-habeas-corpus-coletivopara-m\%C3\%A3es.-Qual-o-impacto-da-decisao .Acesso em: 20.07.2018.

MENDES, Soraia da Rosa. (Re)Pensando a Criminologia: reflexões sobre um novo paradigma desde a epistemologia feminista. Disponível em: http://repositorio.unb.br/bitstream/10482/11867/1/2012_SoraiadaRosaMendes.pdf Acesso em: 20 de julho de 2018.

Saraiva, 2014.

Soraia da Rosa. Criminologia feminista: novos paradigmas. São Paulo:

ONU. Regras das Nações Unidas para o tratamento de mulheres presas e medidas não privativas de liberdade para mulheres infratoras - Regras de Bangkok. Disponível em: http://www.justica.gov.br/seus-direitos/politica-penal/cooperacao-internacional-2/traducaonao-oficial-das-regras-de-bangkok-em-11-04-2012.pdf. Acesso em 19.07.2018.

PANCIERI, Aline; BOITEUX, Luciana. Traficantes Grávidas no Banco dos Réus: Uma Análise Crítica do Controle Penal Sobre Mulheres Em Situação de Maternidade no Rio de Janeiro. Disponível em: http://www.en.wwc2017.eventos.dype.com.br/resources/anais/1499216169_ARQUIVO_Trafi cantesGravidasnoBancodosReus.AlinePancieri.pdf . Acesso em: 19.07.2018.

REZENDE, Grazielle Caroline Veloso. Fatores que Influenciam as Mulheres à Maternidade: Construto Biopsicossocial ou Escolha Ética?. Disponível em: http://cressmg.org.br/hotsites/Upload/Pics/cc/cc1b4f7a-0f95-4eea-8602-75ce0fa17be9.pdf Acesso em: 19.07. 2018. 